\title{
Arresting Prostate Cancer Growth by Targeting the Androgen Receptor and MAGE-A1 1
}

\section{Elizabeth M. Wilson*}

Laboratories for Reproductive Biology, Department of Pediatrics, Lineberger Comprehensive Cancer Center, Department of Biochemistry and Biophysics, University of North Carolina, Chapel Hill, North Carolina, USA

Important questions concerning the hormonal regulation of prostate cancer growth include: Can the androgen receptor (AR) drive prostate tumor growth independent of androgen, and can drug therapies that target androgen biosynthetic enzymes provide a long term cure for prostate cancer?

Prostate cancer begins as a hormone-dependent tumor driven by dihydrotestosterone (DHT), the most potent naturally occurring androgen. DHT is produced locally in the prostate primarily by the action of $5 \alpha$-reductase that converts testosterone, the major circulating but less potent form of androgen [1]. DHT is also produced by a backdoor pathway from androstanediol [2-4]. AR bound to DHT activates androgen-dependent genes by binding androgen response element DNA in enhancer and promoter regions. A key step in AR transactivation of target genes is the androgen-dependent $\mathrm{AR} \mathrm{NH}_{2}$ - and carboxyl-terminal (N/C) interaction mediated by $\mathrm{AR} \mathrm{NH}_{2}$-terminal FXXLF motif binding to activation function 2 in the carboxyl-terminal AR ligand binding domain [5-7]. AR function as a ligand-activated transcription factor requires the coordinated actions of coregulatory proteins.

The requirement for androgen in AR mediated prostate cancer growth is indicated by the temporary remission of tumor growth after androgen deprivation therapy. The eventual regrowth of castrationrecurrent prostate cancer refractory to antihormonal therapies suggests that AR signaling is restored during prostate cancer progression. Many lines of evidence support this and suggest that AR continues to drive castration-recurrent tumor growth despite the ineffectiveness of antiandrogen therapy. However, it is not clear how the low circulating androgen environment of prostate cancer cells enhances AR signaling and how this can be blocked.

The effectiveness of small inhibitory RNA knockdown of AR in blocking prostate cancer cell growth in culture has helped maintain a focus on AR as a key target for the development of new prostate cancer therapies $[8,9]$. Recent evidence states that prostate tumor cells produce their own active androgen that involves up-regulation of genes in the biosynthetic pathway supports the idea that AR remains dependent on androgen for its transcriptional activity $[3,4,10,11]$. Increased intratumoral androgen production provides a mechanism for continued AR signaling in the low circulating androgen environment resulting from androgen deprivation therapy. The ineffectiveness of antiandrogens in arresting the growth of castration-recurrent prostate cancer may be explained by locally produced high affinity active androgens that out-compete lower affinity antiandrogens delivered from the circulation.

Worldwide efforts continue to identify new inhibitors of AR mediated gene transcription and the intratumoral production of androgen. However, whether targeting androgen biosynthetic enzymes will ultimately be effective in curing the patient remains elusive. The recent success of the FDA approved abiraterone acetate, an irreversible inhibitor of $17 a$-hydroxylase/17,20 lyase (P450c17) [12,13], has provided only temporary remission with the eventual regrowth of the tumor. Enzyme inhibitors such as abiraterone acetate may incompletely inhibit their target enzymes and allow sufficient androgen production to maintain AR function. Alternatively, AR may acquire the ability to activate genes and drive prostate cancer growth in a relative deficiency of androgen.

Prostate cancers acquire a variety of survival mechanisms in the hypoxic environment associated with androgen deprivation therapy to enhance the development of castration-recurrent growth Amplification of the AR gene and increased expression of coactivators allows AR to function in a low androgen environment [14-16]. In a few cases, AR mutations in the ligand binding domain expand the range of steroids that can activate AR. These mechanisms maintain AR as the central molecule driving the growth and progression of prostate cancer. However, is it possible that a sufficiently high level of an AR coregulator can bypass the requirement for AR?

An example of increased AR coactivator expression that appears to supplant the requirement for $\mathrm{AR}$ in the growth of castration-recurrent prostate cancer is melanoma antigen-A11 (MAGE-11). MAGE-11 was first identified as a cancer- testis antigen expressed solely in primates. MAGE-11 interacts with the AR FXXLF motif, the same motif that mediates the androgen-dependent AR N/C interaction [17]. MAGE-11 amplifies AR transcriptional activity through its interactions with p300 and p160 coactivators $[18,19]$. The levels of MAGE-11 increase during prostate cancer progression due to hypomethylation of a $\mathrm{CpG}$ island at the transcription start site of the MAGE-11 gene [20,21]. This is evident both in the CWR22 xenograft model of human prostate cancer that undergoes a similar pattern of tumor remission and regrowth after castration, as well as in approximately $1 / 3$ of a relatively small cadre of castration-recurrent prostate cancer patients [20]. In both systems, the increase in MAGE-11 mRNA greatly exceeded the increase in AR mRNA. Moreover, one patient had several orders of magnitude higher levels of MAGE-11 mRNA measured by quantitative real-time RT-PCR, yet there was no detectable AR mRNA. This suggests that sufficiently high levels of MAGE-11 can substitute for a functional AR in promoting the growth and progression of prostate cancer.

The studies point to a need to identify the mechanisms amplified

*Corresponding author: Elizabeth M. Wilson, Laboratories for Reproductive Biology, Department of Pediatrics, Lineberger Comprehensive Cancer Center Department of Biochemistry and Biophysics, University of North Carolina, Chapel Hill, North Carolina, USA, Tel: 919-966-5168; Fax: 919-966-2203; E-mail: emw@med.unc.edu

Received April 22, 2012; Accepted April 23, 2012; Published April 24, 2012

Citation: Wilson EM (2012) Arresting Prostate Cancer Growth by Targeting the Androgen Receptor and MAGE-A11. J Steroids Horm Sci 3:e108. doi:10.4172/2157 7536.1000e108

Copyright: @ 2012 Wilson EM. This is an open-access article distributed unde the terms of the Creative Commons Attribution License, which permits unrestricted use, distribution, and reproduction in any medium, provided the original author and source are credited. 
Citation: Wilson EM (2012) Arresting Prostate Cancer Growth by Targeting the Androgen Receptor and MAGE-A11. J Steroids Horm Sci 3:e108. doi:10.4172/2157-7536.1000e108

in a given prostate cancer patient, be it AR or coregulator, and develop a multi-pronged therapeutic approach that targets $A R$, the enzymes required for androgen biosynthesis, as well as MAGE-11 or other coregulators. The carboxyl-terminal region of MAGE-11 that interacts with the AR FXXLF motif is predicted to have an ordered structure with multiple $\alpha$-helices. The ordered structure of MAGE-11 may provide a new target for drug therapy needed to establish a cure for prostate cancer.

\section{References}

1. Askew EB, Gampe RT Jr, Stanley TB, Faggart JL, Wilson EM (2007) Modulation of androgen receptor activation function 2 by testosterone and dihydrotestosterone. J Biol Chem 282: 25801-25816.

2. Biswas MG, Russell DW (1997) Expression cloning and characterization of oxidative 17beta- and 3alpha-hydroxysteroid dehydrogenases from rat and human prostate. J Biol Chem 272: 15959-15966.

3. Mohler JL, Titus MA, Bai S, Kennerley BJ, Lih FB, et al. (2011) Activation of the androgen receptor by intratumoral bioconversion of androstanediol to dihydrotestosterone in prostate cancer. Cancer Res 71: 1486-1496.

4. Mohler JL, Titus MA, Wilson EM (2011) Potential prostate cancer drug target: bioactivation of androstanediol by conversion to dihydrotestosterone. Clin Cancer Res 17: 5844-5849.

5. He B, Kemppainen JA, Wilson EM (2000) FXXLF and WXXLF sequences mediate the $\mathrm{NH} 2$-terminal interaction with the ligand binding domain of the androgen receptor. J Biol Chem 275: 22986-22994.

6. Wilson EM (2009) Androgen Action in Prostate Cancer: Functional motifs of the androgen receptor. Springer, New York, USA.

7. Wilson EM (2011) Analysis of interdomain interactions of the androgen receptor. Methods Mol Biol 776: 113-129.

8. Zegarra-Moro OL, Schmidt LJ, Huang H, Tindall DJ (2002) Disruption of androgen receptor function inhibits proliferation of androgen-refractory prostate cancer cells. Cancer Res 62: 1008-1013.

9. Ponguta LA, Gregory CW, French FS, Wilson EM (2008) Site-specific androgen receptor serine phosphorylation linked to epidermal growth factor-dependent growth of castration-recurrent prostate cancer. J Biol Chem 283: 20989-21001.
10. Mohler JL, Gregory CW, Ford OH, Kim D, Weaver CM, et al. (2004) The androgen axis in recurrent prostate cancer. Clin Cancer Res 10: 440-448.

11. Wilson EM (2009) Androgen Action in Prostate Cancer: Increased expression of genes converting adrenal androgens to testosterone in Castration-Recurrent Prostate Cancer. Springer, New York, USA

12. O’Donnell A, Judson I, Dowsett M, Raynaud F, Dearnaley D, et al. (2004) Hormonal impact of the 17alpha-hydroxylase/C $(17,20)$-lyase inhibitor abiraterone acetate (CB7630) in patients with prostate cancer. $\mathrm{Br} \mathrm{J}$ Cancer 90: $2317-2325$.

13. Attard G, Cooper CS, de Bono JS (2009) Steroid hormone receptors in prostate cancer: a hard habit to break? Cancer Cell 16: 458-462.

14. Linja MJ, Savinainen KJ, Saramäki OR, Tammela TL, Vessella RL, et al. (2001) Amplification and overexpression of androgen receptor gene in hormonerefractory prostate cancer. Cancer Res 61: 3550-3555.

15. Gregory CW, He B, Johnson RT, Ford OH, Mohler JL, et al. (2001) A mechanism for androgen receptor-mediated prostate cancer recurrence after androgen deprivation therapy. Cancer Res 61: 4315-4319.

16. Gregory CW, Johnson RT Jr, Mohler JL, French FS, Wilson EM (2001) Androgen receptor stabilization in recurrent prostate cancer is associated with hypersensitivity to low androgen. Cancer Res 61: 2892-2898.

17. Bai S, He B, Wilson EM (2005) Melanoma antigen gene protein MAGE-11 regulates androgen receptor function by modulating the interdomain interaction. Mol Cell Biol 25: 1238-1257.

18. Askew EB, Bai S, Hnat AT, Minges JT, Wilson EM (2009) Melanoma antigen gene protein-A11 (MAGE-11) F-box links the androgen receptor NH2-termina transactivation domain to $\mathrm{p} 160$ coactivators. J Biol Chem 284: 34793-34808.

19. Askew EB, Bai S, Blackwelder AJ, Wilson EM (2010) Transcriptional synergy between melanoma antigen gene protein-A11 (MAGE-11) and p300 in androgen receptor signaling. J Biol Chem 285: 21824-21836.

20. Karpf AR, Bai S, James SR, Mohler JL, Wilson EM (2009) Increased expression of androgen receptor coregulator MAGE-11 in prostate cancer by DNA hypomethylation and cyclic AMP. Mol Cancer Res 7: 523-535

21. Wilson EM (2010) Androgen receptor molecular biology and potential targets in prostate cancer. Ther Adv Urol 2: 105-117. 